\title{
Competition among Escherichia coli Strains for Space and Resources
}

\author{
Sarah-Jo Paquette ${ }^{1,2}$, Rahat Zaheer ${ }^{3}\left(\mathbb{0}\right.$, Kim Stanford $^{1}{ }^{1}$, James Thomas ${ }^{2}$ and Tim Reuter ${ }^{1, *(1)}$ \\ 1 Alberta Agriculture and Forestry, \#100-5401 1st Ave. S, Lethbridge, AB T1J 4V6, Canada; \\ sarahjo.paquette@uleth.ca (S.-J.P.); kim.stanford@gov.ab.ca (K.S.) \\ 2 Department of Biological Sciences, University of Lethbridge, 4401 University Drive W, \\ Lethbridge, AB T1K 3M4, Canada; thomas@uleth.ca \\ 3 Agriculture and AgriFood Canada, \#205-5403 1st Ave. S, Lethbridge, AB T1J 4P4, Canada; \\ rahat.zaheer@canada.ca \\ * Correspondence: tim.reuter@gov.ab.ca
}

Received: 20 September 2018; Accepted: 30 October 2018; Published: 2 November 2018

\begin{abstract}
Shiga toxin-producing Escherichia coli (STEC) are a subgroup of E. coli causing human diseases. Methods to control STEC in livestock and humans are limited. These and other emerging pathogens are a global concern and novel mitigation strategies are required. Habitats populated by bacteria are subjected to competition pressures due to limited space and resources but they use various strategies to compete in natural environments. Our objective was to evaluate non-pathogenic E. coli strains isolated from cattle feces for their ability to out-compete STEC. Competitive fitness of non-pathogenic E. coli against STEC were assessed in competitions using liquid, agar, and nutrient limiting assays. Winners were determined by enumeration using O-serogroup specific quantitative $P C R$ or a semi-quantitative grading. Initial liquid competitions identified two strong non-pathogenic competitors (O103F and O26E) capable of eliminating various STEC including O157 and O111. The strain O103F was dominant across permeable physical barriers for all tested E. coli and STEC strains indicating the diffusion of antimicrobial molecules. In direct contact and even with temporal disadvantages, O103F out-competed STEC O157E. The results suggest that O103F or the diffusible molecule(s) it produces have a potential to be used as an alternative STEC mitigation strategy, either in medicine or the food industry.
\end{abstract}

Keywords: E. coli; Shiga toxin producing E. coli; competition; probiotics; interactions; warfare

\section{Introduction}

In 1934 the Russian biologist, Georgii Gause conceived that rivals for limiting resources cannot coexist and that one competitor would become "prey" and the other "predator", demonstrating this concept using yeast and protozoa [1]. This became known as the "Competitive Exclusion Principle" [2], which states "Complete competitors cannot coexist". Accordingly, in an environment where one species has an advantage such as increased growth rate, the species with the advantage (predator) will dominate over the long term and eliminate the weaker competitor (prey).

Environments populated by Escherichia coli are subject to competition pressures due to limited availability of space and resources. Bacteria use various weapons to ensure their survival [3] and ability to compete which can take place in any natural environment $[4,5]$. Competition can be exploitative where a predator restricts nutrients and starves the prey [4]. Effective exploiters can prevail in competitions, but weak exploiters can also out-compete a vigorous exploiter using interference competition. Interference-based competition uses antagonistic factors produced by competitors such as toxins to prevent or remove competitors from their environment [4]. The competitive outcome depends 
on the dynamic of the competitive interactions, which is often referred as the "rock-paper-scissors" game (Figure 1) [6].

\begin{tabular}{|c|c|c|}
\hline Competition & Winner & Loser \\
\hline Producer vs Sensitive & Producer & Sensitive \\
\hline Producer vs Resistant & Resistant & Producer \\
\hline Sensitive vs Resistant & Sensitive & Resistant \\
\hline
\end{tabular}
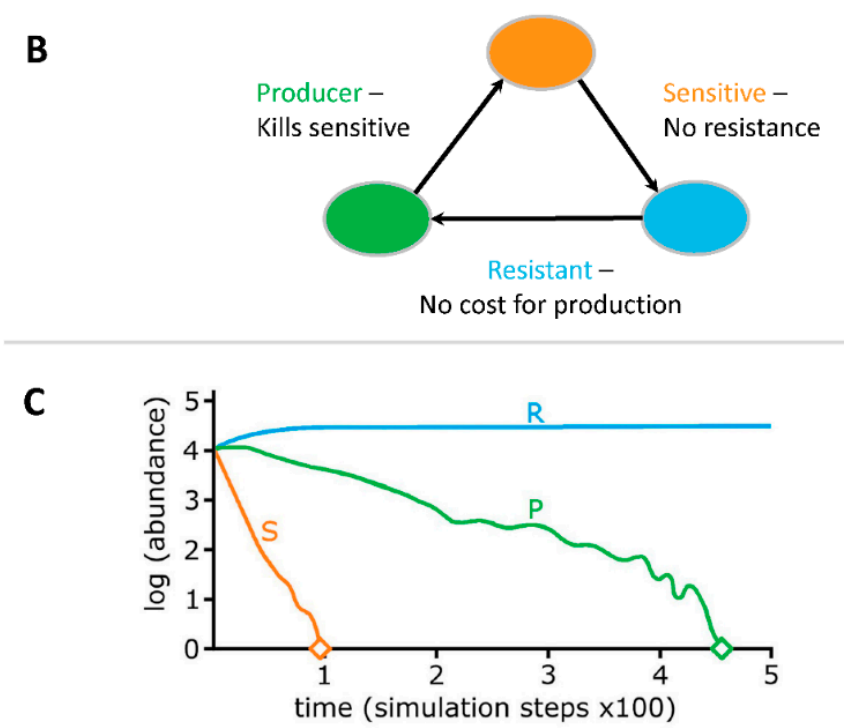

Figure 1. "Rock-Paper-Scissor" game of competition dynamics. Note: $\mathrm{R}=$ resistant, $\mathrm{P}=$ producer and $\mathrm{S}=$ Sensitive. Compartments $(\mathbf{A}),(\mathbf{B})$ and $(\mathbf{C})$ are adapted from references [6-8], respectively.

Producers generate molecules such as antibiotics, specialized enzymes, and colicins that can kill, prevent growth and/or disrupt signal cascades [4]. However, there is a high cost to producing molecules such as colicins and in a two-strain system, removal of the sensitive strain provides an advantage to the producer (Figure 1A,B) [8]. In contrast, sensitive strains do not have any metabolic cost for either producing or resisting, providing a metabolic advantage in competitions with resistant strains, while succumbing in the presence of producers. Resistant strains, avoid metabolic costs associated with molecule production, but there are costs associated with resistance, which are less than production but higher compared to sensitive strains. In a three-strain dynamic with no spatial structure (well-mixed conditions, such as an aquatic environment) competitive advantage shifts to resistant strains (Figure 1C) [8,9].

Interference based competition can be divided into independent and contact-dependent methods [10]. Contact independent mechanisms rely on diffusible compounds such as bacteriocins and antibiotics to damage and/or kill competing bacteria or signals such as quorum-sensing molecules to facilitate interactions between bacteria. Direct-contact interactions also occur with contact-dependent growth inhibition (CDI), which requires specific receptors on competing cells or type VI secretion systems (T6SS), which do not need specific targets $[10,11]$. E. coli has been shown to possess all three types of interference-based competitive mechanisms [11-13].

Escherichia coli is a commensal bacterium and part of the gastrointestinal microbiota in humans and livestock. While many E. coli are considered harmless or beneficial, others such as Shiga-toxin producing E. coli (STEC) are virulent causing gastrointestinal diseases [14]. STEC are classified by the ability to produce at least one Shiga toxin (Stx) [15] and can cause severe infections such as hemolytic uremic syndrome or hemorrhagic colitis $[16,17]$. 
Ruminants, especially cattle, are a major host of STEC and many technologies to control STEC in livestock have been evaluated including vaccines, direct-fed microbials, and tannins [18-20]. Ultimately, none of these has shown consistent efficacy. As well, treatment options for humans infected with STEC are limited as some antibiotics may increase Shiga toxin production and/or release by inducing the bacterial SOS response [21]. As dependable methods to control STEC in cattle and humans are not yet available, use of non-pathogenic E. coli predator strains to out-compete and control pathogenic STEC strains may have potential. Almost 100 years ago, E. coli strain Nissle was recovered from the gut of a soldier and has been subsequently used as a probiotic to mitigate intestinal infections in humans [22]. Similarly, another study reported E. coli O157:H7 mitigation in cattle after the use of a direct-fed microbial consisting of non-pathogenic E. coli strains [23].

Our primary objectives were to investigate competitive non-pathogenic E. coli strains isolated from cattle feces with the potential to control STEC such as O157:H7 and investigate the competitive mechanisms utilized by these predator strains and potentially identify if these strains were producers and/or resistant.

\section{Materials and Methods}

\subsection{Bacterial Strains: Cultures, Media and Culture Conditions}

All strains used in this study were isolated from feces collected from transport trailers of slaughter cattle at two Alberta slaughter plants [24] (Table 1). E. coli were streaked from glycerol stocks onto MacConkey Agar (MAC, BD, Sparks, NV, USA). Plates were incubated overnight $(16-18 \mathrm{~h})$ at $37^{\circ} \mathrm{C}$. A single colony was selected from each plate and inoculated into $10 \mathrm{~mL}$ E. coli broth (EC) (EMD Millipore, Etobicoke, ON, Canada) and incubated overnight at $37^{\circ} \mathrm{C}$ statically (liquid competition) or with shaking at $150 \mathrm{rpm}$ (other competitions).

\subsection{Competition Experiments}

Various E. coli strains were examined for competitive fitness using tests to identify strong candidates that prevented or modified growth of STEC.

\subsubsection{Liquid Competition}

The liquid competition was adapted from that previously described [25]. Overnight cultures of each strain were diluted to a starting cell density of $\sim 1000$ cells based on optical density (OD) measured at a wavelength of $600 \mathrm{~nm}$. Both competitors ( $100 \mu \mathrm{L}$ each) were added to EC for a final starting volume of $10 \mathrm{~mL}$ and grown $24 \mathrm{~h}$ at $37^{\circ} \mathrm{C}$, statically. A pure culture control $(100 \mu \mathrm{L}$ in EC) of each competitor was also prepared and grown under the same conditions as the competition cultures. After $24 \mathrm{~h}, 100 \mu \mathrm{L}$ from each competition and control were inoculated into $9.9 \mathrm{~mL}$ of fresh $\mathrm{EC}$ and grown for another $24 \mathrm{~h}$, with this repeated for a total of 14 days. Samples were removed (100 $\mu \mathrm{L}$ of culture) at time $=0$, 3,7 , and 14 days for quantitative real-time PCR (qPCR) monitoring of copy numbers of O-serogroup specific gene sequence to extrapolate cell density of a particular strain in the culture. Primers, probes, and PCR conditions were performed, as previously described [25].

\subsubsection{Omelette Method}

After overnight incubation, one competitor was streaked across a $4 \mathrm{~mm}$ MAC plate using a cotton swab. The hereinafter bottom strain was then incubated for $24 \mathrm{~h}$ at $37^{\circ} \mathrm{C}$. After $24 \mathrm{~h}$, the agar was flipped and 3 strains were streaked perpendicular to the bottom strain and separated from the bottom strain by the thickness of the agar (Figure 2). Plates were then incubated for an additional $24 \mathrm{~h}$ at $37^{\circ} \mathrm{C}$ and examined for zones of no growth directly over the bottom strain and graded using a scale of 1-to-10, with 1 being no growth over the bottom strain and 10 being full growth. Plates were incubated for an additional 6 days (7 days total) at $37^{\circ} \mathrm{C}$ to monitor changes in zones of growth inhibition. 
A second trial was performed, as described above, with the following change: Agar thickness of MAC plates was increased to $7 \mathrm{~mm}$ and $10 \mathrm{~mm}$ and compared to the original $4 \mathrm{~mm}$ thickness.

Table 1. Escherichia coli strains utilized in this study.

\begin{tabular}{|c|c|c|c|c|c|c|c|c|c|c|}
\hline Rank & \multicolumn{2}{|c|}{ Serogroup } & H-Type & Toxin & eae & hlyA & Liquid & Omelette & $\begin{array}{c}\text { Plug n' } \\
\text { Prey }\end{array}$ & $\begin{array}{l}\text { Discussed in } \\
\text { Manuscript }\end{array}$ \\
\hline Strongest & \multicolumn{2}{|c|}{ O103F } & $\mathrm{NM}$ & - & - & - & $\sqrt{ }$ & $\sqrt{ }$ & $\sqrt{ }$ & $\sqrt{ }$ \\
\hline \multirow{3}{*}{ Strong } & \multicolumn{2}{|c|}{$\mathrm{O} 26 \mathrm{E}$} & H9 & - & - & - & $\sqrt{ }$ & $\sqrt{ }$ & & $\sqrt{ }$ \\
\hline & \multirow{2}{*}{\multicolumn{2}{|c|}{$\begin{array}{l}\text { O178A } \\
\text { O178B }\end{array}$}} & H7 & - & NT & NT & & $\sqrt{ }$ & & $\sqrt{ }$ \\
\hline & & & NT & - & - & - & & $\sqrt{ }$ & & \\
\hline \multirow{28}{*}{ Weak } & \multirow{5}{*}{$\mathrm{O} 26$} & A & NT & - & - & NT & $\sqrt{ }$ & & & \\
\hline & & B & NT & - & + & NT & $\sqrt{ }$ & & & \\
\hline & & $\mathrm{C}$ & H18 & - & - & - & $\sqrt{ }$ & & & \\
\hline & & $\mathrm{D}$ & H11 & stx 1 & + & + & $\sqrt{ }$ & $\sqrt{ }$ & & \\
\hline & & $\mathrm{F}$ & NM & - & + & - & $\sqrt{ }$ & & & \\
\hline & \multirow{3}{*}{$\mathrm{O} 45$} & $\mathrm{~A}$ & $\mathrm{H} 4$ & - & - & - & & $\sqrt{ }$ & & \\
\hline & & B & NT & stx 1 & + & NT & & $\sqrt{ }$ & & \\
\hline & & C & NT & - & - & NT & & $\sqrt{ }$ & & \\
\hline & \multicolumn{2}{|c|}{ O51A } & $\mathrm{NM}$ & - & - & - & & $\sqrt{ }$ & & \\
\hline & \multirow{5}{*}{ O103 } & $\mathrm{A}$ & NM & - & + & + & $\sqrt{ }$ & & & \\
\hline & & B & NM & - & + & + & $\sqrt{ }$ & & & \\
\hline & & C & NM & - & + & + & $\sqrt{ }$ & & & \\
\hline & & $\mathrm{D}$ & H38 & - & - & - & $\sqrt{ }$ & & & \\
\hline & & $\mathrm{E}$ & $\mathrm{NM}$ & - & + & + & $\sqrt{ }$ & $\sqrt{ }$ & & \\
\hline & \multirow{6}{*}{ O111 } & A & NM & stx 1 & + & + & $\sqrt{ }$ & $\sqrt{ }$ & & \\
\hline & & B & NM & stx 1 & + & + & $\sqrt{ }$ & & & \\
\hline & & C & H8 & stx 1 & + & + & $\sqrt{ }$ & & & \\
\hline & & $\mathrm{D}$ & H8 & stx 1 & + & + & $\sqrt{ }$ & & & \\
\hline & & $\mathrm{E}$ & NM & stx 1 & + & + & $\sqrt{ }$ & & & \\
\hline & & $\mathrm{F}$ & NM & stx 1 & + & + & $\sqrt{ }$ & $\sqrt{ }$ & & $\sqrt{ }$ \\
\hline & \multirow{2}{*}{ O145 } & $\mathrm{A}$ & NM & stx 1 & + & + & & $\sqrt{ }$ & & \\
\hline & & B & $\mathrm{H} 25$ & - & + & + & & $\sqrt{ }$ & & \\
\hline & \multirow{6}{*}{ O157 } & A & $\mathrm{H} 7$ & stx $1 \mathcal{E} 2$ & + & + & $\sqrt{ }$ & $\sqrt{ }$ & & $\sqrt{ }$ \\
\hline & & B & NT & stx $1 \mathcal{E} 2$ & + & NT & $\sqrt{ }$ & & & \\
\hline & & C & NT & stx $1 \mathcal{E} 2$ & + & NT & $\sqrt{ }$ & & & \\
\hline & & $\mathrm{D}$ & H7 & stx $1 \mathcal{E} 2$ & + & + & $\sqrt{ }$ & \multirow{3}{*}{$\sqrt{ }$} & \multirow{3}{*}{$\sqrt{ }$} & \multirow{3}{*}{$\sqrt{ }$} \\
\hline & & $\mathrm{E}$ & NT & stx 2 & + & NT & $\sqrt{ }$ & & & \\
\hline & & $\mathrm{F}$ & NT & stx $1 \mathcal{E} 2$ & + & NT & $\sqrt{ }$ & & & \\
\hline
\end{tabular}

Note: NT $=$ Not tested, Symbol: $-=$ tested and not present,$+=$ tested and present. Multiple representative strains of each serotype were used in this study. $(\sqrt{ })$ checkmark symbol identifies which strains were used in each test and which strains are discussed in the manuscript. STEC (Shiga toxin-producing Escherichia coli) were defined as Escherichia coli strains positive for at least one shiga toxin gene by PCR.

\subsubsection{Plug ' $n$ ' Prey}

The competition assay was performed in $2 \mathrm{~mL}$ tubes prepared with slants of $200 \mu \mathrm{L}$ MAC agar. Slants were overlaid with $800 \mu \mathrm{L}$ saline buffer $(0.9 \% \mathrm{NaCl})$. Overnight cultures for both trials were prepared as previously described and were diluted to an OD $600 \mathrm{~nm}$ of 0.100 and grown to an OD $600 \mathrm{~nm}$ of $0.3-0.4$ at exponential cell growth. Actively growing cells were diluted to a total starting cell density of $\sim 1000$ cells. In the first trial $100 \mu \mathrm{L}$ of each competitor was inoculated into the $2 \mathrm{~mL}$ tubes at the same time (Figure 3). Samples were taken at time points 0, 2, 4, and 6 days. Tube contents were divided into supernatant and slant and individually analyzed by qPCR targeting O-serogroup specific gene to monitor the copy numbers. The second trial set-up was equivalent to the first except one strain was inoculated into the $2 \mathrm{~mL}$ tube $3 \mathrm{~h}$ prior to the competitor. 


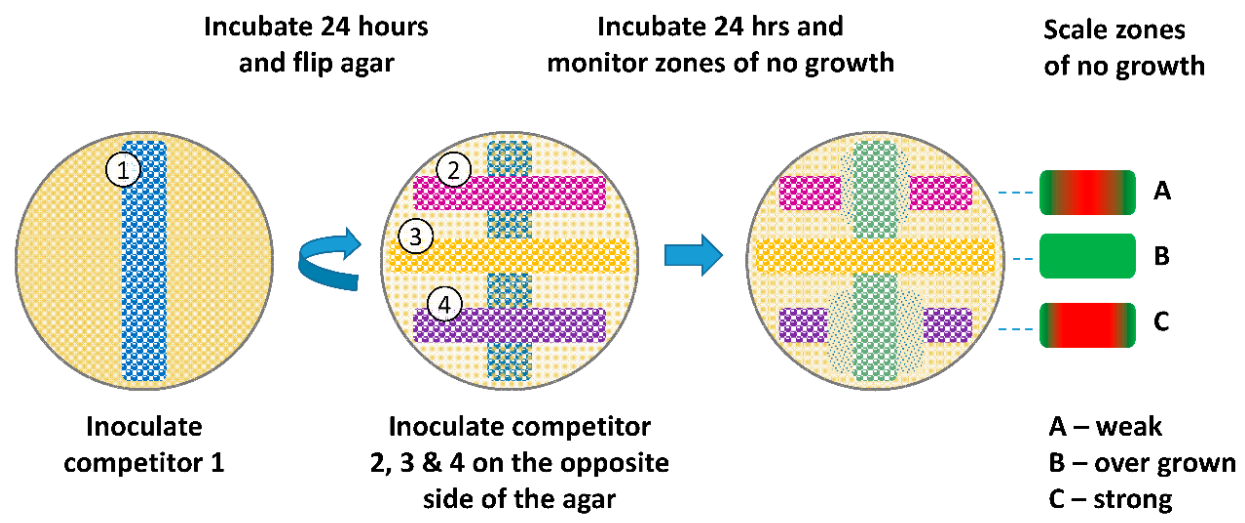

Total time of incubation 7 days with monitoring of no growth zones

Figure 2. Schematic of Omelette method. Competitor strains were streaked on both surfaces of a $4 \mathrm{~mm}$ MAC plate. The bottom strain was streaked and grown for $24 \mathrm{~h}$ at $37^{\circ} \mathrm{C}$. After $24 \mathrm{~h}$, the agar was flipped and three strains were streaked perpendicular to the bottom strain, separated by the thickness of the agar. Plates were then incubated for an additional $24 \mathrm{~h}$ and examined for zones of no growth graded by a scale of 1-to-10. Plates were incubated for another 6 days ( 7 days total) to monitor changes in zones of no growth. Agar thickness of 4, 7, and $10 \mathrm{~mm}$ were evaluated.

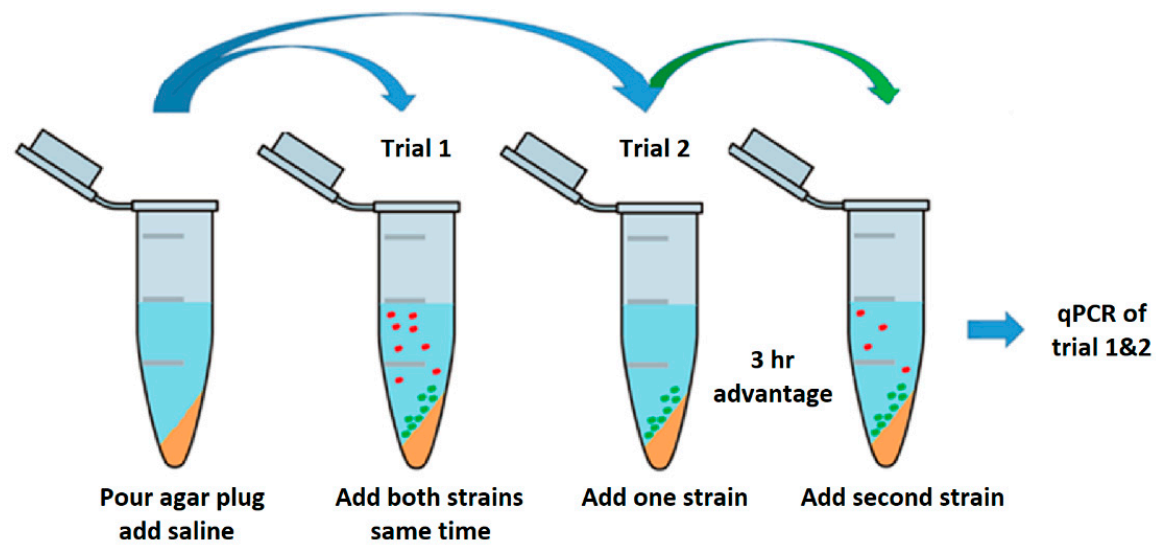

Figure 3. Schematic of Plug ' $n$ ' Prey. A $2 \mathrm{~mL}$ tube prepared with slants of $200 \mu \mathrm{L}$ MAC agar. Slants were overlaid with $800 \mu \mathrm{L}$ saline buffer $(0.9 \%)$. In the first trial, overnight cultures were diluted to an OD $600 \mathrm{~nm}$ of 0.100 and grown to an OD $600 \mathrm{~nm}$ of $0.3-0.4$ to ensure actively growing cells. Actively growing cells were diluted to a starting concentration of $\sim 1000$ cells and $100 \mu \mathrm{L}$ of each competitor was inoculated at same time. The second trial was performed, as described, with the following change: One strain was inoculated $3 \mathrm{~h}$ prior to the competitor. Samples for both trials were taken at time points $0,2,4$, and 6 days. Tube contents were divided into supernatant and slant and individually analyzed by qPCR monitoring copy numbers of $\mathrm{O}$-serogroup specific gene fragment amplification.

\subsection{Statistical Analysis}

Numerical data generated by qPCR for the liquid competition and plug ' $n$ ' prey were examined for normal distribution and the data were log transformed prior to analyses. Serogroup, competition, control, and interactions were determined for both liquid and plug ' $\mathrm{n}$ ' prey using a mixed linear model (Proc Mixed, SAS 9.4, SAS Institute Inc., Cary, NC, USA). Given $p$ values $<0.05$ were considered significant. 


\section{Results}

\subsection{Liquid Competition}

The qPCR enumerations from 72 competitions of either $\mathrm{O} 103$ (six non-pathogenic strains tested) vs. O157 (six STEC tested) or O26 (five non-pathogenic strains and one STEC) vs. O111 (six STEC) identified strong non-pathogenic E. coli competitors that were able to eliminate O157 and O111 (Figure 4). The O103 vs. O157 competitions identified a strong strain, O103F that eliminated all six opponent strains of $\mathrm{O} 157$ tested to levels undetectable by qPCR by day 14 . Similarly, a strong non-pathogenic $\mathrm{O} 26, \mathrm{O} 26 \mathrm{E}$, eliminated five of six pathogenic $\mathrm{O} 111$ with only $\mathrm{O} 111 \mathrm{~B}$ remaining after 14 days and present in lower numbers $\left(10^{3}\right)$ compared to O26E $\left(10^{7}\right)$. Growth of $103 \mathrm{~F}$ was greater than each $\mathrm{O} 157$ tested and growth of O26E exceeded that of each $\mathrm{O} 111(p<0.05)$. Growth of pure culture controls for each competition set O103F, O157A-F, and O26E, O111A-F did not differ $(p>0.05)$ and all were present over the 14 days (Figure 4).

\subsection{Omelette Method}

The semi-quantitative data from the first trial (4 mm MAC plates) with various strains also identified the $\mathrm{O} 103 \mathrm{~F}$ from the liquid competition as a strong competitor (Supplemental, Figure S1). $\mathrm{O} 103 \mathrm{~F}$ had a strong zone of no growth at $24 \mathrm{~h}$ and maintained the zone for seven days, while the $\mathrm{O} 157$ initially had a less pronounced zone of no growth at $24 \mathrm{~h}$ and at day seven the strong O103F was grown over the original no growth zone of O157A. From the $4 \mathrm{~mm}$ thickness trial, another strong competitor was identified, E. coli O178A, which maintained a strong zone of growth inhibition over seven days against the O103F and O26E strains from the liquid competition (Supplemental, Figure S2a). Furthermore, both the O103F and O178A strains maintained stronger zones of no growth compared to O26E, which had a less prominent zone of no growth (Figure S2a,b).

The $24 \mathrm{~h}$ semi-quantitative data from the second trial (four, seven, and $10 \mathrm{~mm}$ MAC plates) with O103F, O178A, O111F, and O157A demonstrated that at four mm agar thickness, all four strains had a strong zone of no growth and as agar thickness increased the size of the zones of growth inhibition varied by strain (Figure 5). O157A did not maintain a zone of no growth at seven mm and all three competing strains (O103F, O178A, and O111F) had solid growth when O157A was the bottom competitor. In comparison, $\mathrm{O} 111 \mathrm{~F}$ at $7 \mathrm{~mm}$ maintained the zone of no growth only for O157A and O178A, but not O103F. Both O178A and O103F maintained a narrowed zone of no growth at seven $\mathrm{mm}$ but at $10 \mathrm{~mm}$ thickness, O103F still maintained a zone of no growth for O111F and O157A and very limited growth for O178A. In contrast, O178A at $10 \mathrm{~mm}$ maintained the zone of no growth only for O157A with both O111F and O103F growing over the bottom O178A strain.

\subsection{Plug ' $n$ ' Prey}

The qPCR enumerations for plug ' $n$ ' prey demonstrated the ability of O103F to out-compete O157E when nutrients were limited (Figure 6). The first trial (I) with O103F and O157E in competition demonstrated that by day six, O103F was 10 times more numerous in both matrices, slant and supernatant, but differences in growth between O103F an O157E were found only for the supernatant $(p<0.05)$. The second experiment (IIa) with O157E having a three $\mathrm{h}$ advantage demonstrated that O103F overcame the disadvantage by day two and had 10 times higher concentrations of cells by day six, although overall growth did not differ $(p>0.05)$ between O103F and O157E. When O103F had the three h advantage (trial IIb) it won by 30 times higher concentrations in comparison to the O157E for the slant environment and was 40 times higher in the supernatant $(p<0.05)$. Comparing the O157 pure culture controls to $\mathrm{O} 157$ across all three competitions showed higher growth $(p<0.05)$ controls of O157E, as compared to competition for trial IIb. In contrast, even in competition, O103F grew similar to the O103F control in all trials $(p>0.05)$. 


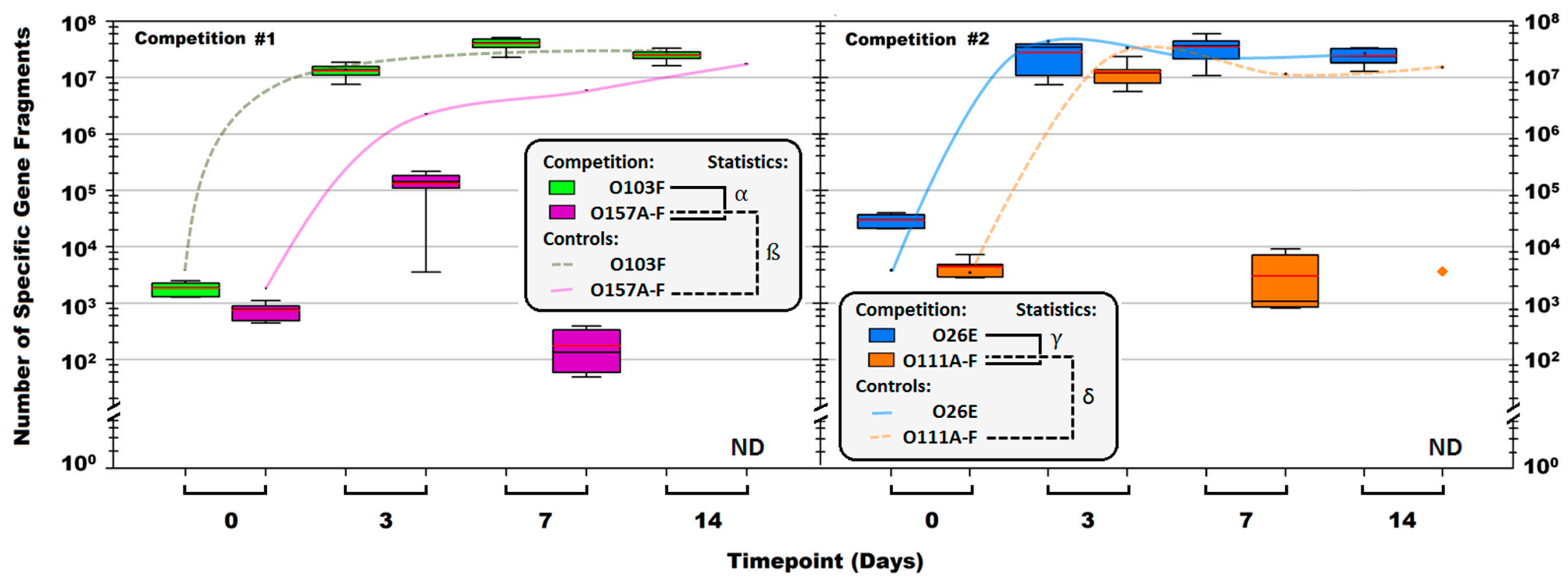

Figure 4. Total number of Escherichia coli O103F, O157A-F, O26E and O111A-F specific gene fragments in each liquid competition and corresponding pure culture controls calculated using qPCR. The boxes are serogroup specific enumerations for competition cultures and the lines are the pure culture controls. Note: ND = not detected. Red line in the boxes is the average proportion for the group and black line in the boxes is the median. The $>$ symbol denotes the O111B strain that was still present after 14 days. Symbols: $\alpha, \beta, \gamma$, and $\delta$ denote a significant difference between: O103F and O157A-F in competition, O157A-F in competition and O157A-F controls, O26E and O111A-F in competition and O111A-F in competition and O111A-F controls, respectively $(p<0.05)$. 


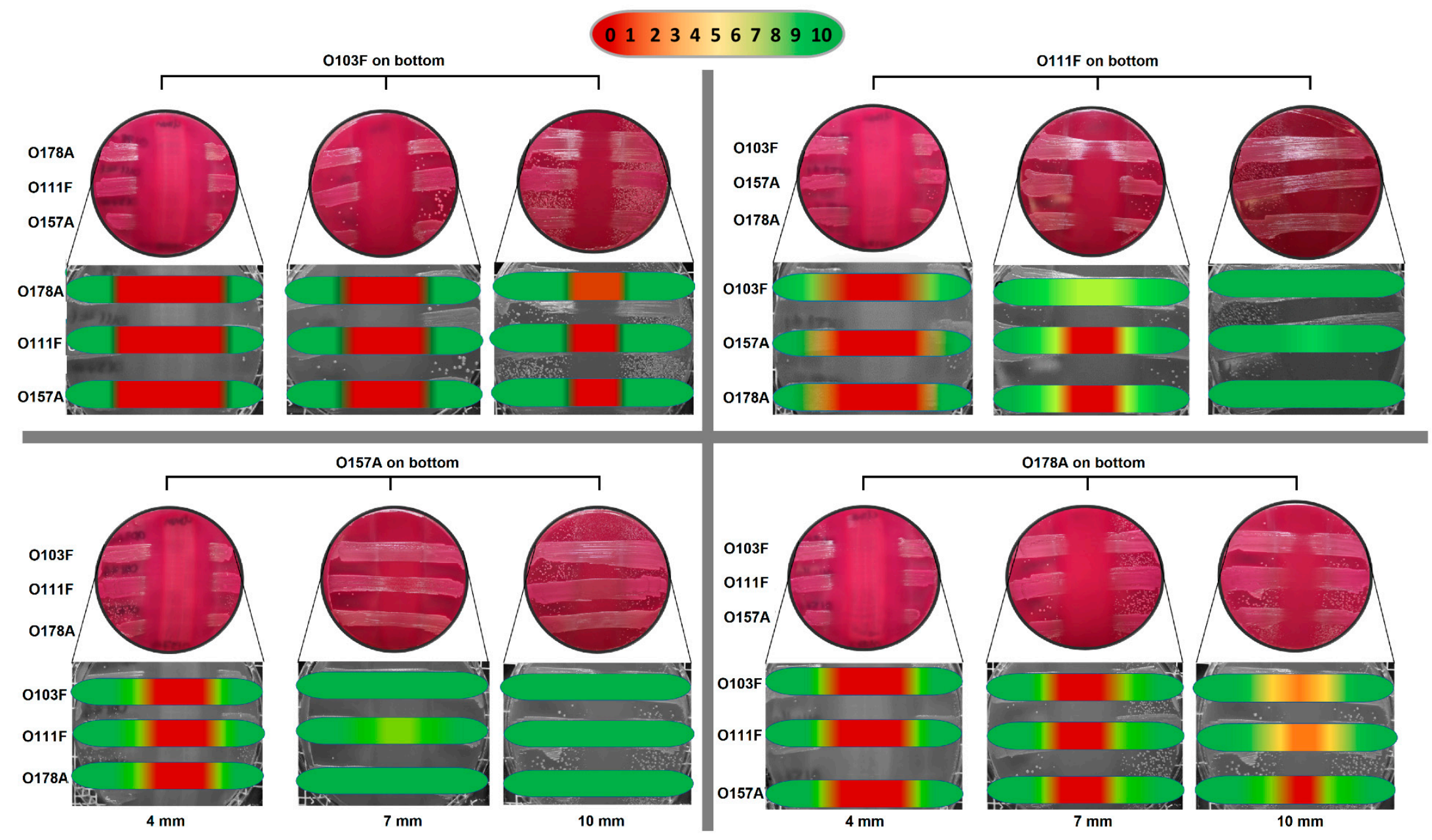

Figure 5. Omelette method results for Escherichia coli O103F, O111F, O157A, and O178A with varying plate thickness (4, 7, and 10 mm) against each other examining zones of no growth. Growth zones are graded beneath each plate with red (0) representing no growth to green (10) representing no inhibition of growth. 


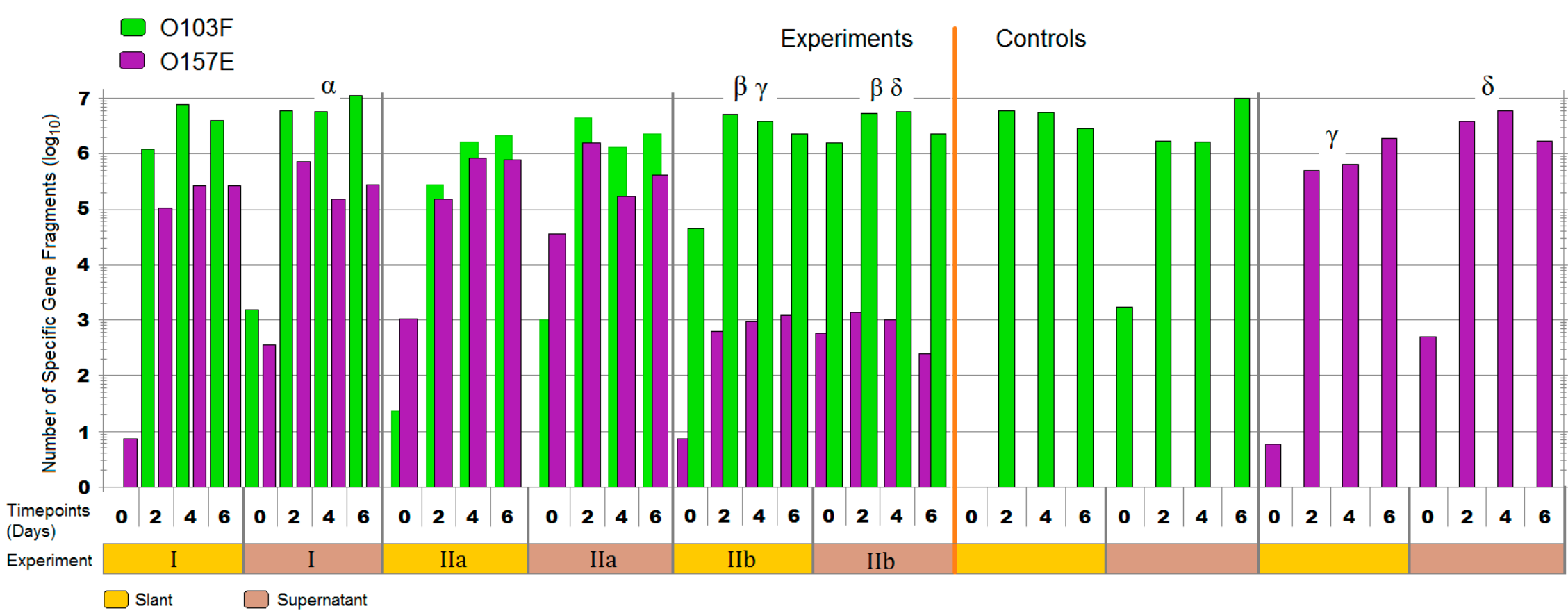

Figure 6. The total number of Escherichia coli O103F and O157E specific gene fragments in the supernatant and on the agar slant, across three plug ' $\mathrm{n}$ ' prey experiments in comparison to the controls at each time point. Note: $\mathbf{I}=$ O103F and O157E added at the same time (bars side by side), IIa $=$ O157E $3 \mathrm{~h}$ advantage over O103F (O157E bar on top), IIb $=$ O103F $3 \mathrm{~h}$ advantage over O157E (O103F bar on top). Timepoint 0 is first time point after addition of both competitors. Symbols: $\alpha, \beta, \gamma$, and $\delta$ denote a significant difference between: O103F and O157E in experiment I—supernatant, O103F and O157E in experiment IIb—slant and supernatant, O157E in experiment IIb and O157E control—slant and O157E in experiment IIb and O157E control—supernatant, respectively $(<0.05)$. 


\section{Discussion}

In three different settings, the competition of E. coli strains for resources and/or space was monitored. Using liquid media permitted cell-to-cell contact, while solid media created a physical barrier between opposing strains. Previous research reported that interference-based competitions can be contact-dependent or contact independent [10], although when using a physical barrier only a producing predator would win competitions for space. During liquid competitions, both distant and close combat tactics were applicable. However, within the homogeneous distribution of cells and nutrients in liquid, it cannot be determined if coordinated strategies by strains took place or if one competitor conquered due to an advantage in metabolism and/or proliferation.

\subsection{Liquid Competition}

Using liquid competition, we identified two non-pathogenic E. coli strains (belonging to serogroups $\mathrm{O} 103$ and O26), which significantly reduced opponent strains to below limits of detection or resulted in a 4- $\log _{10}$ reduction of six different strains each of O157 (vs. O103F) and O111 (vs. O26E) $(p<0.05)$. This finding, that non-pathogenic E. coli have the ability to outcompete pathogenic E. coli strains, is in accordance with a previous study reporting that calves treated with probiotic E. coli shed significantly less O26:H11 and O111:NM STEC compared to untreated calves [26]. Furthermore, strong competitors within our E. coli strains were previously identified [25]. However, O26C, a strong competitor previously reported [25] was weaker compared to O26E identified in this study.

Competition can be exploitative or interference based [4] and it is possible that the O103F and O26E identified in the liquid competition are great exploiters and simply out-competed their competitors for resources. However, the qPCR enumerations for all the pure-culture controls suggest otherwise since all strains proliferated to similar concentrations in EC without competition $(p>0.05)$, suggesting that the liquid competition results are due to interference and not exploitation.

E. coli is known to have both contact independent and dependent interference-based systems and have been shown to produce various bacteriocins known as colicins [12], may possess a CDI system [11] and/or harbor a T6SS system [13]. In a pure culture of planktonic bacteriocin producing E. coli, $0.5-3 \%$ of the population express bacteriocin spontaneously [27]. Possibly, O103F and O26E expressed bacteriocins out-compete the O157 and O111 strains tested. CDI systems in E. coli have also been shown to be active in liquid culture as E. coli EC93 inhibited E. coli K-12 cells [28]. Moreover, CDI systems require specific receptors on the competing bacterial cells that are often found on closely related strains or within the same species, suggesting the CDI mechanism could be employed during competition. Contrary to CDI systems, the T6SS targets cells non-specifically by using physical forces to deliver effectors [10]. Here, T6SS was an unlikely mode of action, since a highly-active T6SS competitor was unable to target sensitive strains in liquid medium in contrast to a solid medium [29], which suggests that, in liquid competitions, bacteria do not use T6SS, but rely on other mechanisms.

\subsection{Omelette Method}

The results from the semi-quantitative omelette assay revealed the production of diffusible toxins or noxious products since the competitor strains were separated by a physical barrier preventing contact-dependent competition. Agar plates are often used to visualize competitive interactions due to the manifestation of visible phenotypes that identify competition winners [9]. Similar to the results of the liquid competition, O103F produced a stronger diffusible substance than the competitors. Here, we also identified another strong contact-independent strain, (O178A) with zones of no growth similar in size to those of O103F. In comparison, the O26E identified in the liquid competition did not have as strong of a zone of no growth as O103F, suggesting the presence of a weaker diffusible substance. The second trial further demonstrated the strength of the O103F diffusible substance through distance. O103F maintained the strongest zone of no growth as agar thickness increased for all strains tested including O178A from the first trial. Overall, while O103F appeared to have the strongest 
diffusible substance and best resistance, all strains tested showed an initial zone of no growth at $24 \mathrm{~h}$, suggesting that they all produced a detrimental substance capable of preventing growth of other E. coli, which conforms to previous reports that E. coli produces diffusible toxins [12,30]. Furthermore, various studies have examined E. coli strains for production of bacteriocins and the percentage of strains that produce bacteriocins can vary from $10 \%$ to $70 \%$ depending on the environment where they were isolated [31].

Bet-hedging is a survival tactic used by bacteria, where they express phenotypes randomly instead of in reaction to environmental cues [32]. Bacteriocin production has been shown to occur at a low frequency in growing producer populations [27] and a recent study has shown that E. coli colicin producers use bet-hedging as a survival strategy [32]. A previous study suggested that such a low-level production could be considered a pre-emptive attack against sensitive strains [33]. Possibly, the diffusible molecule produced by $\mathrm{O} 103 \mathrm{~F}$ and others was spontaneously produced during the first $24 \mathrm{~h}$ of the omelette study providing an advantage to the bottom strain prior to addition of the competitors. Furthermore, low-level producers in an established colony can signal sister cells to mount a collective attack against invading cells [33]. Potentially, if some O103F cells in the established colony were already producing bacteriocins, these cells could have sensed the competitors and signaled sister O103F cells, mounting stronger attacks against the "invading cells" indicated by wider zones of no growth. On the other hand, bacteriocins have been suggested to act first as a signaling and repelling molecule rather than being lethal and possibly the competitors of O103F, which were repelled by the molecule produced by O103F [34].

Based on the classification of competitors in a bacterial warfare as either producers, resistant or sensitive [6] (Figure 1), all strains tested in this study appear to be producers. However, revealing the characteristics of a producer, strain O103F can also grow over other strains over time, implying that $\mathrm{O} 103 \mathrm{~F}$ is both a strong producer and a resistant strain. Bacteriocin production is based on the translation of three genes encoding toxin, immunity, and lysis [32]. Therefore, production confers immunity and likely any diffusible molecule will be paired with the production of immunity molecules to prevent the killing of sister cells. E. coli strains have been shown to produce more than one colicin and microcin [30] and possibly O103F is resistant to some bacteriocins and/or diffusible(s) from other E. coli strains because $\mathrm{O} 103 \mathrm{~F}$ produces a similar diffusible, which confers immunity. On the other hand, immunity can also be conferred by mutations that either alter receptors or the translocation system for the bacteriocin [6,30] and O103F may be resistant to diffusible(s) of other E. coli strains due to these types of mutations. Future research on the specific O103F diffusible(s) may determine if (I) the diffusible is a bacteriocin, (II) the diffusible is killing or signaling competitors and (III) the diffusible immunity is conferred by production of the diffusible or due to mutations that grant immunity, which may further elucidate the strength of the O103F strain as a competitor.

\subsection{Plug 'n' Prey}

This study was designed to examine the effect of limiting nutrients on competition outcome between the identified strong O103F and the previously tested O157E strain. Limiting nutrients did not change the overall outcome in all the trials and O103F won all the competitions, including when inoculated with a three $h$ disadvantage into vials containing the nutrients but growth between O103F and O157E was only different $(p<0.05)$ for trial I-supernatant and trial IIb-both matrices. Perhaps, the lack of nutrients in plug ' $n$ ' prey affected the ability of O103F to compete effectively once nutrients were depleted. Previous research has shown that bacteriocin production in a lactic acid bacterium was modified when the carbon source changed and bacteriocin production increased or decreased depending on the carbon source [35]. Conceivably, the same modification of bacteriocin production may be seen by limiting the carbon source.

Ultimately, O103F won both competitions having either an advantaged or disadvantaged access to limited nutrients. It overcame the O157E advantage to win overall and prevented O157E from growing past the inoculation density of 1000 cells when $\mathrm{O} 103 \mathrm{~F}$ had the advantage. Having the advantage, 
O103F won all competitions, which is in accordance with a previous study that reported that an "established" colony is more successful mounting attacks against invading competitors [33]. With a three $\mathrm{h}$ advantage, O103F suppressed the growth of O157E over six days by preventing O157E from growing beyond 1000 cells. However, the "established" O157E was not able to prevent O103F from growing, which is contrary to previous reports [33]. In the end, after a three $h$ advantage O103F was able to maintain a competitive advantage, while O157E was not able to fortify the nutrient source during this time, further demonstrating the predatory strength of O103F compared to O157E. Future studies with different nutrients and different advantage times may further elucidate if and how the competitive mechanisms of $\mathrm{O} 103 \mathrm{~F}$ are affected by nutrition.

Bacteria, such as E. coli are found in almost every habitat on earth and face fierce competition for space and resources $[5,10,36]$. In order to ensure their survival, bacteria use various competitive mechanisms which can be exploitative and/or interference based [4,10]. Among others, habitats for virulent $E$. coli are humans and their food sources. During medical treatment and along the food production chain, control of proliferation, and/or colonization by virulent $E$. coli remains a challenge.

STEC are a significant food borne pathogen [37] and are classified by the ability to produce at least one Stx [15]. Cattle are considered the main reservoir for STEC and STEC carriage in cattle is asymptomatic due to a lack of receptors for Stx [38]. On the other hand, Stx is considered a main virulence trait to cause human disease [39] since Stx binds to globotriaosylceramide (Gb3) present on endothelial cells [37]. Benefiting from natural competitiveness, E. coli champions may offer mechanisms to mitigate STEC as protective culture and/or additive within the food chain or as a probiotic treatment option for human infections.

It should be noted that highly-competitive non-pathogenic E. coli may have the potential to become STEC if infected with a Stx bacteriophage. However, a study examining the ability of various stx2-phages to infect $E$. coli from different pathotypes found that while all strains could be infected with Stx-phages, not all Stx-phages infected every E. coli and phage integration was rarely stable [40]. Other studies examining Stx-phage infection on various food sources found that for Stx-phage infection to occur both the donor and recipient need to be present in high concentrations not typically found in food samples [41,42]. Together, these studies suggest that while Stx-phage infection is possible: (1) It is unlikely to occur and (2) rarely is phage integration stable. Unless there is stable integration, the phage DNA is removed, rendering E. coli a non-STEC. Furthermore, identification of the diffusible(s) produced by these highly competitive non-pathogenic $E$. coli would mitigate the risk by removing the need to use the bacteria and instead only use their products.

This study identified a strong $\mathrm{O} 103$ competitor based on three different experimental settings against various strains including STEC O111 and STEC O157. The exact mode of action used by O103F to out-compete other E. coli strains remains unknown but O103F likely produces at least one diffusible substance that affects the viability of other E. coli. Diffusible molecules produced by E. coli can be colicins, antibiotics, or quorum sensing molecules [4], and are potential alternatives to antibiotics [43]. Future evaluation of E. coli O103F may identify the effective diffusible substance(s) produced by this strain and may provide an alternative STEC mitigation strategy as therapeutic treatment or protective culture in the food industry.

\section{Conclusions}

Among living organisms, fierce battles exist to secure habitats and natural resources or even for survival. Between bacterial competitors, predators, and prey have developed several strategies to protect their existence and survival combat interactions that might ultimately be correlated to energy conversion efficiencies and the capacity to proliferate. Our observations revealed a number of highly competitive E. coli strains, but ended with one exclusive champion. Over 100 years ago, a champion (E. coli Nissle) from a human host was discovered to battle virulent bacteria and has been successfully marketed as a probiotic, mitigating human infections since then. Novel emerging pathogens are a global concern and new approaches for mitigation strategies require further evaluation. 
Here, numerous Shiga-toxin producing E. coli strains were outcompeted by a non-pathogenic E. coli strain that was isolated from cattle feces. This non-pathogenic strain shows the potential to be used to control pathogenic E. coli that compromise health and/or food safety.

Supplementary Materials: The following are available online at http:/ / www.mdpi.com/2306-7381/5/4/93/s1, Figure S1. Omelette method results for $\mathrm{O} 103$ and $\mathrm{O} 157$ at $24 \mathrm{~h}$ and 7 days against each other examining zones of clearing, Figure S2. Omelette method results for O26, O103 and O178 against each other examining zones of clearing at day 7.

Author Contributions: Conceptualization, S.-J.P., J.T. and T.R.; methodology, S.-J.P., R.Z. and T.R.; formal analysis, S.-J.P. and K.S.; investigation, S.-J.P.; resources, T.R.; data curation, S.-J.P.; writing —original draft preparation, S.-J.P.; writing-review and editing, S.J.P., R.Z., K.S., J.T. and T.R.; visualization, S.-J.P., R.Z. and T.R.; supervision, J.T. and T.R.; project administration, T.R.; funding acquisition, K.S. and T.R.

Funding: This research was supported by Growing Forward 2, grant number TR 9037070.

Acknowledgments: We would like to acknowledge and thank Susanne Trapp and Yidong Graham for their invaluable assistance in the laboratory and Shaun Cook and Yongxiang Zhang for their willingness to share their expertise and knowledgeable discussions.

Conflicts of Interest: The authors declare no conflict of interest. The funders had no role in the design of the study; in the collection, analyses, or interpretation of data; in the writing of the manuscript, or in the decision to publish the results.

\section{References}

1. Gause, G.F. The Struggle for Existence; Dover Publications: Mineola, NY, USA, 2003; pp. 1-163.

2. Hardin, G. The competitive exclusion principle. Science 1960, 131, 1292-1297. [CrossRef] [PubMed]

3. Majeed, H.; Lampert, A.; Ghazaryan, L.; Gillor, O. The weak shall inherit: Bacteriocin-mediated interactions in bacterial populations. PLOS ONE 2013, 8, e63837. [CrossRef] [PubMed]

4. Stubbendieck, R.M.; Straight, P.D. Multifaceted interfaces of bacterial competition. J. Bacteriol. 2016, 198, 2145-2155. [CrossRef] [PubMed]

5. De Muinck, E.J.; Stenseth, N.C.; Sachse, D.; vander Roost, J.; Rønningen, K.S.; Rudi, K.; Trosvik, P. context-dependent competition in a model gut bacterial community. PLoS ONE 2013, 8, e67210. [CrossRef] [PubMed]

6. Riley, M.A.; Wertz, J.E. Bacteriocins: Evolution, ecology, and application. Annu. Rev. Microbiol. 2002, 56, 117-137. [CrossRef] [PubMed]

7. Hibbing, M.E.; Fuqua, C.; Parsek, M.R.; Peterson, S.B. Bacterial competition: Surviving and thriving in the microbial jungle. Nat. Rev. Microbiol. 2010, 8, 15-25. [CrossRef] [PubMed]

8. Kerr, B.; Riley, M.A.; Feldman, M.W.; Bohannan, B.J.M. Local dispersal promotes biodiversity in a real-life game of rock-paper-scissors. Nature 2002, 418, 171-174. [CrossRef] [PubMed]

9. Stubbendieck, R.M.; Vargas-Bautista, C.; Straight, P.D. Bacterial communities: Interactions to scale. Front. Microbiol. 2016, 7. [CrossRef] [PubMed]

10. Garcia, E.C. Contact-dependent interbacterial toxins deliver a message. Curr. Opin. Microbiol. 2018, 42, 40-46. [CrossRef] [PubMed]

11. Aoki, S.K.; Diner, E.J.; de Roodenbeke, C.T.; Burgess, B.R.; Poole, S.J.; Braaten, B.A.; Jones, A.M.; Webb, J.S.; Hayes, C.S.; Cotter, P.A.; et al. A widespread family of polymorphic contact-dependent toxin delivery systems in bacteria. Nature 2010, 468, 439-442. [CrossRef] [PubMed]

12. Majeed, H.; Gillor, O.; Kerr, B.; Riley, M.A. Competitive interactions in Escherichia coli populations: The role of bacteriocins. ISME J. 2011, 5, 71-81. [CrossRef] [PubMed]

13. Journet, L.; Cascales, E. The type VI secretion system in Escherichia coli and related species. EcoSal Plus 2016, 7. [CrossRef] [PubMed]

14. Russo, T.A.; Johnson, J.R. Medical and economic impact of extraintestinal infections due to Escherichia coli: Focus on an increasingly important endemic problem. Microbes. Infect. 2003, 5, 449-456. [CrossRef]

15. Rahal, E.A.; Fadlallah, S.M.; Nassar, F.J.; Kazzi, N.; Matar, G.M. Approaches to treatment of emerging Shiga toxin-producing Escherichia coli infections highlighting the O104:H4 serotype. Front. Cell. Infect. Microbiol. 2015, 5, 24. [CrossRef] [PubMed] 
16. Cleary, T.G. The role of Shiga-toxin-producing Escherichia coli in hemorrhagic colitis and hemolytic uremic syndrome. Semin. Pediatr. Infect. Dis. 2004, 15, 260-265. [CrossRef] [PubMed]

17. Brusa, V.; Aliverti, V.; Aliverti, F.; Ortega, E.E.; de la Torre, J.H.; Linares, L.H.; Sanz, M.E.; Etcheverría, A.I.; Padola, N.L.; Galli, L.; et al. Shiga toxin-producing Escherichia coli in beef retail markets from Argentina. Front. Cell. Infect. Microbiol. 2012, 2, 171. [CrossRef] [PubMed]

18. Stanford, K.; Hannon, S.; Booker, C.W.; Jim, G.K. Variable efficacy of a vaccine and direct-fed microbial for controlling Escherichia coli O157:H7 in feces and on hides of feedlot cattle. Foodborne Pathog. Dis. 2014, 11, 379-387. [CrossRef] [PubMed]

19. Stephens, T.P.; Stanford, K.; Rode, L.M.; Booker, C.W.; Vogstad, A.R.; Schunicht, O.C.; Jim, G.K.; Wildman, B.K.; Perrett, T.; McAllister, T.A. Effect of a direct-fed microbial on animal performance, carcass characteristics and the shedding of Escherichia coli $\mathrm{O} 157$ by feedlot cattle. Anim. Feed Sci. Technol. 2010, 158, 65-72. [CrossRef]

20. Jin, L.; Wang, Y.; Iwaasa, A.D.; Li, Y.; Xu, Z.; Schellenberg, M.P.; Liu, X.L.; McAllister, T.A.; Stanford, K. Purple prairie clover (Dalea purpurea Vent) reduces fecal shedding of Escherichia coli in pastured cattle. J. Food Prot. 2015, 78, 1434-1441. [CrossRef] [PubMed]

21. Pacheco, A.; Sperandio, V. Shiga toxin in enterohemorrhagic E. coli: Regulation and novel anti-virulence strategies. Front. Cell. Infect. Microbiol. 2012, 2, 81. [CrossRef] [PubMed]

22. Sonnenborn, U. Escherichia coli strain Nissle 1917-from bench to bedside and back: History of a special Escherichia coli strain with probiotic properties. FEMS Microbiol. Lett. 2016, 363, 212. [CrossRef] [PubMed]

23. Zhao, T.; Doyle, M.; Harmon, B.G.; Brown, C.A.; Mueller, P.O.E.; Parks, A.H. Reduction of carriage of enterohemorrhagic Escherichia coli O157:H7 in cattle by inoculation with probiotic bacteria. J. Clin. Microbiol. 1998, 36, 641-647. [PubMed]

24. Stanford, K.; Johnson, R.P.; Alexander, T.W.; McAllister, T.A.; Reuter, T. Influence of season and feedlot location on prevalence and virulence factors of seven serogroups of Escherichia coli in feces of Western-Canadian slaughter cattle. PLoS ONE 2016, 11, e0159866. [CrossRef] [PubMed]

25. Conrad, C.C.; Stanford, K.; McAllister, T.A.; Thomas, J.; Reuter, T. Competition during enrichment of pathogenic Escherichia coli may result in culture bias. FACETS 2016, 1, 114-126. [CrossRef]

26. Zhao, T.; Tkalcic, S.; Doyle, M.P.; Harmon, B.G.; Brown, C.A.; Zhao, P. Pathogenicity of enterohemorrhagic Escherichia coli in neonatal calves and evaluation of fecal shedding by treatment with probiotic Escherichia coli. J. Food Prot. 2003, 66, 924-930. [CrossRef] [PubMed]

27. Majeed, H.; Ghazaryan, L.; Herzberg, M.; Gillor, O. Bacteriocin expression in sessile and planktonic populations of Escherichia coli. J. Antibiot. 2015, 68, 52-55. [CrossRef] [PubMed]

28. Aoki, S.K.; Pamma, R.; Hernday, A.D.; Bickham, J.E.; Braaten, B.A.; Low, D.A. Contact-dependent inhibition of growth in Escherichia coli. Science 2005, 309, 1245-1248. [CrossRef] [PubMed]

29. Hood, R.D.; Singh, P.; Hsu, F.; Güvener, T.; Carl, M.A.; Trinidad, R.R.; Silverman, J.M.; Ohlson, B.B.; Hicks, K.G.; Plemel, R.L.; et al. A type VI secretion system of Pseudomonas aeruginosa targets a toxin to bacteria. Cell Host Microbe 2010, 7, 25-37. [CrossRef] [PubMed]

30. Budič, M.; Rijavec, M.; Petkovšek, Ž.; Žgur-Bertok, D. Escherichia coli bacteriocins: Antimicrobial efficacy and prevalence among isolates from patients with bacteraemia. PLoS ONE 2011, 6, e28769. [CrossRef] [PubMed]

31. Gordon, D.M. The Natural History of Bacteriocins. In The Bacteriocins: Current Knowledge and Future Prospects; Dorit, R.L., Roy, S.M., Riley, M.A., Eds.; Caister Academic Press: Norfolk, UK, 2016; pp. 1-10; ISBN 9781910190371.

32. Bayramoglu, B.; Toubiana, D.; van Vliet, S.; Inglis, R.F.; Shnerb, N.; Gillor, O. Bet-hedging in bacteriocin producing Escherichia coli populations: The single cell perspective. Sci. Rep. 2017, 7, 42068. [CrossRef] [PubMed]

33. Mavridou, D.A.I.; Gonzalez, D.; Kim, W.; West, S.A.; Foster, K.R. Bacteria use collective behavior to generate diverse combat strategies. Curr. Biol. 2018, 28, 345-355. [CrossRef] [PubMed]

34. Chikindas, M.L.; Weeks, R.; Drider, D.; Chistyakov, V.A.; Dicks, L.M. Functions and emerging applications of bacteriocins. Curr. Opin. Biotechnol. 2018, 49, 23-28. [CrossRef] [PubMed]

35. Suganthi, V.; Mohanasrinivasan, V. Optimization studies for enhanced bacteriocin production by Pediococcus pentosaceus KC692718 using response surface methodology. J. Food Sci. Technol. 2015, 52, 3773-3783. [CrossRef] [PubMed] 
36. Russell, A.B.; Peterson, S.B.; Mougous, J.D. Type VI secretion system effectors: Poisons with a purpose. Nat. Rev. Microbiol. 2014, 12, 137-148. [CrossRef] [PubMed]

37. Smith, J.L.; Fratamico, P.M.; Gunther, N.W. Chapter three-Shiga toxin-producing Escherichia coli. Adv. Appl. Microbiol. 2014, 86, 145-197. [CrossRef] [PubMed]

38. Persad, A.K.; LeJeune, J.T. Animal reservoirs of Shiga toxin-producing Escherichia coli. Microbiol. Spectr. 2014, 2. [CrossRef]

39. Rivas, M.; Chinen, I.; Miliwebsky, E.; Masana, M. Risk factors for Shiga toxin-producing Escherichia coli-Associated human diseases. Microbiol. Spectr. 2014, 2. [CrossRef] [PubMed]

40. Tozzoli, R.; Grande, L.; Michelacci, V.; Ranieri, P.; Maugliani, A.; Caprioli, A.; Morabito, S. Shiga toxin-converting phages and the emergence of new pathogenic Escherichia coli: A world in motion. Front. Cell. Infect. Microbiol. 2014, 4, 80. [CrossRef] [PubMed]

41. Imamovic, L.; Jofre, J.; Schmidt, H.; Serra-Moreno, R.; Muniesa, M. Phage-mediated Shiga toxin 2 gene transfer in food and water. Appl. Environ. Microbiol. 2009, 75, 1764-1768. [CrossRef] [PubMed]

42. Nyambe, S.; Burgess, C.; Whyte, P.; Bolton, D. An investigation of vtx2 bacteriophage transduction to different Escherichia coli patho-groups in food matrices and nutrient broth. Food Microbiol. 2017, 68, 1-6. [CrossRef] [PubMed]

43. Chassaing, B.; Cascales, E. Antibacterial weapons: Targeted destruction in the microbiota. Trends. Microbiol. 2018, 26, 329-338. [CrossRef] [PubMed]

(C) 2018 by the authors. Licensee MDPI, Basel, Switzerland. This article is an open access article distributed under the terms and conditions of the Creative Commons Attribution (CC BY) license (http:/ / creativecommons.org/licenses/by/4.0/). 